Research Article

\title{
Experimental Investigation on Embedding Strength Perpendicular to Grain of Parallel Strand Bamboo
}

\author{
Junwen Zhou $\mathbb{D}^{1,2}$ Dongsheng Huang $\mathbb{D}^{2}{ }^{2}$ Yang Song, and Chun $\mathrm{Ni}^{3}$ \\ ${ }^{1}$ School of Civil and Architecture Engineering, Changzhou Institute of Technology, Changzhou 213032, China \\ ${ }^{2}$ School of Civil Engineering, Nanjing Forestry University, Nanjing 210037, China \\ ${ }^{3}$ FPInnovations, Vancouver, BC, Canada V6T $1 Z 4$
}

Correspondence should be addressed to Junwen Zhou; zhoujw@czu.cn

Received 7 November 2017; Revised 25 March 2018; Accepted 10 April 2018; Published 13 May 2018

Academic Editor: Nadezda Stevulova

Copyright ( $\odot 2018$ Junwen Zhou et al. This is an open access article distributed under the Creative Commons Attribution License, which permits unrestricted use, distribution, and reproduction in any medium, provided the original work is properly cited.

Parallel strand bamboo (PSB) is a latest construction material; to know more about mechanical properties of PSB, 5 groups of specimens with difference only in bolt diameter were designed to study the impact of the fastener diameter on embedding strength perpendicular to grain of PSB. Based on the tested result, the feasibility for PSB of the theoretical equation in the American code and European code on embedding strength predication was assessed. A controlled displacement was used to load till specimen failure, the stress-displacement curve of all specimens was obtained in terms of the tested results, and the yielding tested strength based on $5 \%$ bolt diameter offset proposed by the American code was found. The tested results showed that the yielding strength perpendicular to grain of PSB was stable, the variable coefficient was between $5.88 \%$ and $13.34 \%$, and the average yielding strength values were 80.84 MPa, 77.40 MPa, 76.52 MPa, 74.20 MPa, and 67.01 MPa, respectively, which decreased with the increase of bolt diameter, and the average yielding strength values are larger than the calculated results using theoretical formula. Therefore, the theoretical equation on embedding yielding strength of wood in the American code and European code applies to PSB.

\section{Introduction}

Nowadays, timber and bamboo buildings again have started gaining attention because low-carbon and ecological concepts are the new architecture tendency. Also, primary construction materials used in modern timber structures are renewable materials and are better than fossil materials such as steel and concrete in thermal performance, which is in conformity with the sustainable development principle $[1,2]$; thus, timber buildings have become a new development trend in recent decades. In northern America, timber buildings are already preferred in low-carbon architecture, and almost $90 \%$ of low-rise buildings are timber structures. Nowadays, more and more midrise and tall timber buildings have been constructed in some countries, such as the most famous 18-storey Brock Commons Student Residence with a height of 53 meters in UBC [3]. The growth period of original structural wood from the time of planting to harvesting is longer, about decades, which is indirectly proportional to the existing demand, especially in Asian countries.

In addition, constructed wood is sparse due to cutting of trees in early stage; hence, bamboo is preferred for its short harvesting period and identical excellent mechanical performance compared with traditional wood.

Bamboo, widely planted in Asia, especially in Southeast Asia, is "the second forestry resource" because of the suitable temperature and humidity in lower geographic latitude.

Bamboo was already used as a construction material about thousand years ago [4]. Bamboo has a short harvesting period of about 3-5 years [5-8]. Bamboo is easily available and has higher mechanical strength compared to wood [9]; however, because of its thin wall and hollow and limited sections, large scale use of raw bamboo is restricted in building structures. As a result, raw bamboo is commonly used in rural houses, simple bridges, water channels, and some landscape architecture. With the progress in technology, some new engineered bamboo materials, such as 


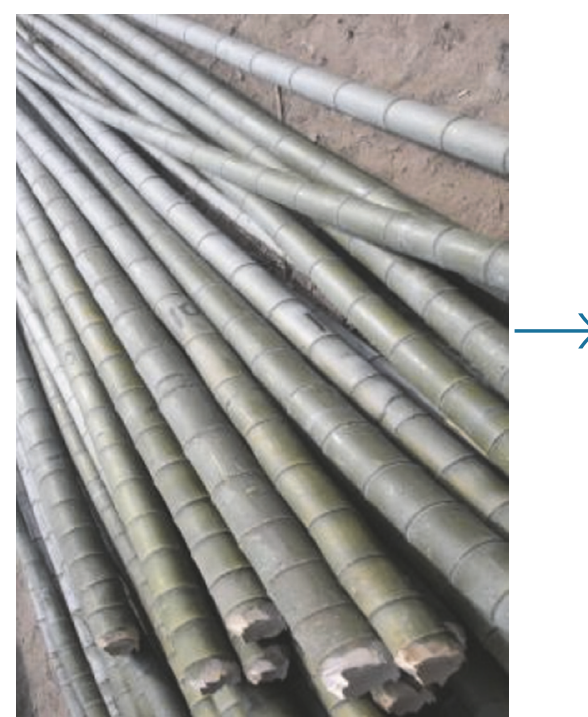

(a)

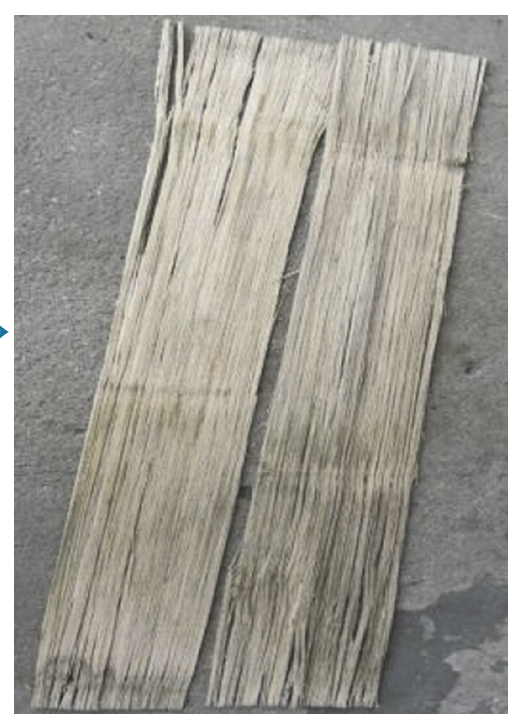

(b)

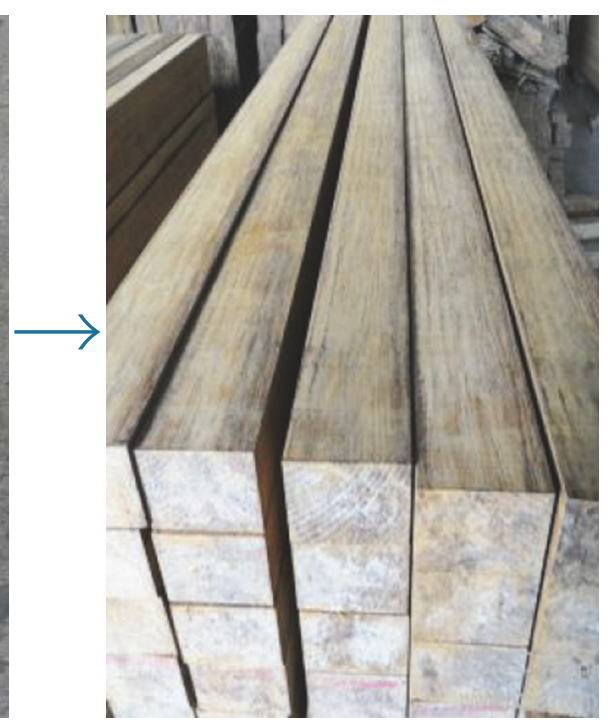

(c)

Figure 1: Manufacturing process of parallel strand bamboo. (a) Raw bamboo. (b) Bamboo fiber bundle. (c) Parallel strand bamboo.

laminated bamboo [10-13] and parallel strand bamboo (PSB) [14-16], have been developed and those materials have a pronounced breakthrough in dimensions and, therefore, have higher load-bearing capacity and posses a better application prospect in building structures.

PSB is a new engineering material made with raw bamboo. At plant, PSB is fabricated in the manufacturing process expressed in Figure 1; first, original bamboo is cut into certain length according to the demand parallel to grain and, then, is rolled into bamboo fiber bundle which is broken in the longitudinal direction and connected in the latitudinal direction, as shown in Figure 1(b). The bamboo fiber bundle is dried to reach a moisture content between $5 \%$ and $10 \%$, immersed in glue well, and then put into billet under pressure and heat, and the fiber is aligned to be in parallel with the length of the member. Once the adhesive of phenolic resin is cured, the bamboo fiber is glued together to form a PSB member. Commonly, the shape of PSB is sheet or prism which is actually determined in terms of practical applications. PSB holds the continuity fiber of bamboo and overcomes some defect of section limit and concentration knot, and as a result, PSB owns the outstanding mechanical performances compared to raw bamboo [16]. A two-storey building has been constructed in China using PSB material [14]. The superiority mentioned above indicates that PSB has a good prospect to be an alternative construction material. At present, some studies on PSB mainly deal with the mechanical performance of small-scale specimens and basic components [15-17], showing that PSB has more superior qualities than engineered wood.

Like wooden buildings, bamboo buildings are also prefabricated structure buildings, and the mechanical performance of connection, such as bearing capacity, and stability are very important, concerning the safety of the overall structure. As a basic connection mode, bolted connection has been used widespread in modern wooden structures, and dowel bearing of wood in connection is the main behavior of bolted connection, impacting the mechanical performance of whole connection. Few studies were performed to determine the four important influence factors, fastener diameter, density of wood, moisture content, and load-to-grain angle, on embedding strength of wood.

Rammer [18] investigated the mechanical performance of embedding strength of hardwoods parallel to grain, and three diameters of steel nail and fastener were tested. The results showed that fastener diameter has affinity on embedding stiffness and no affinity on embedding strength; however, the nail diameter has obvious influence on embedding strength and stiffness. Rammer and Winistorfer [19] proposed the calculating formula, including the moisture content for embedding capacity of wood. Sawata and Yasumura [20] tested the dowel-bearing strength with four kinds of fastener diameter parallel to grain and perpendicular to grain, respectively; the embedding strength is decided based on the $5 \%$ bolt diameter offset method and $5 \mathrm{~mm}$ displacement maximum load, and the result shows that the embedding strength perpendicular to grain increases with the decrease in dowel diameter. Franke and Magnière [21] investigated the embedding behavior of European hardwoods through the testing analysis, and the influence of the load-to-grain angle and fastener diameter was studied. Schweigler et al. [22] studied the embedding performance of fastener with two kinds of diameter on different load-to-grain in the laminated veneer lumber, and the relative mechanical behavior was obtained. Seri et al. [23] concentrated on the embedding performance of glulam with and without glue line wood with two different fastener diameters, and the results show that the fastener diameter and manufacturing method have pronounced influence on the dowel-bearing strength of the specimen.

The dowel-bearing experiment with superiorities of convenience, practicability, and economy is employed to attain some important data; to the author's knowledge, only few studies are available on embedding strength of PSB perpendicular 


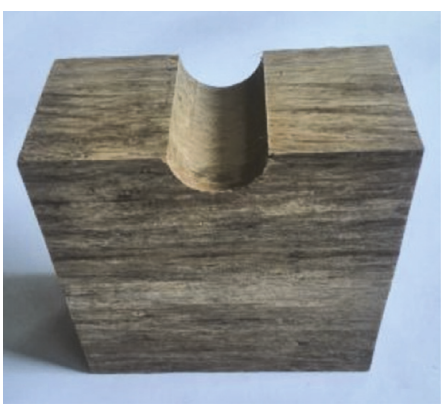

(a)

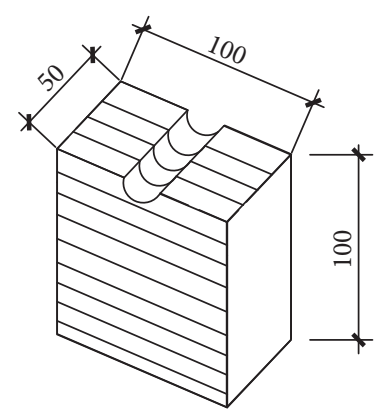

(b)

FIgURE 2: Drawing details of the specimen.

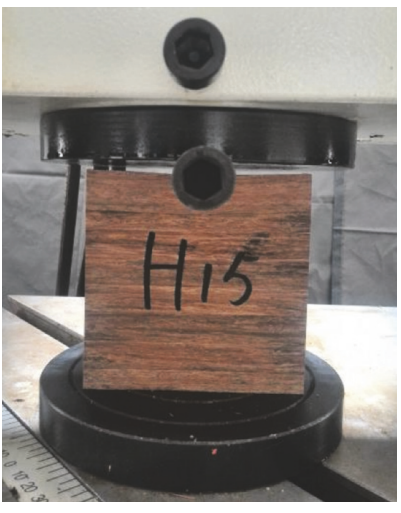

(a)

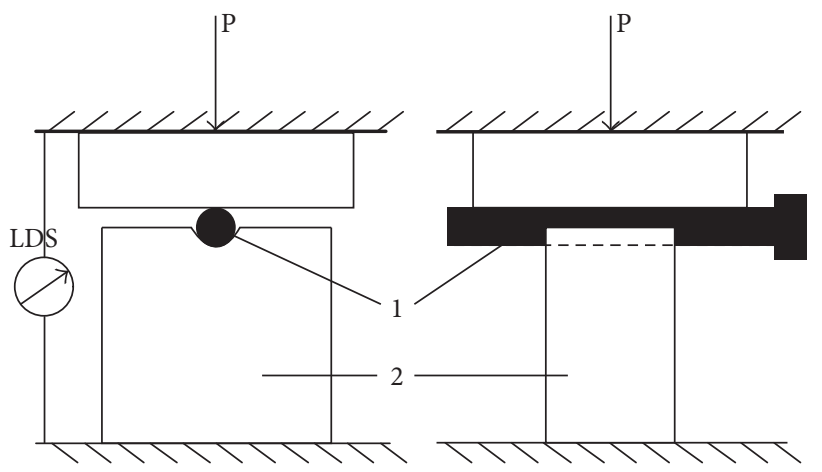

1: fastener

2: specimen

(b)

Figure 3: Experimental setup.

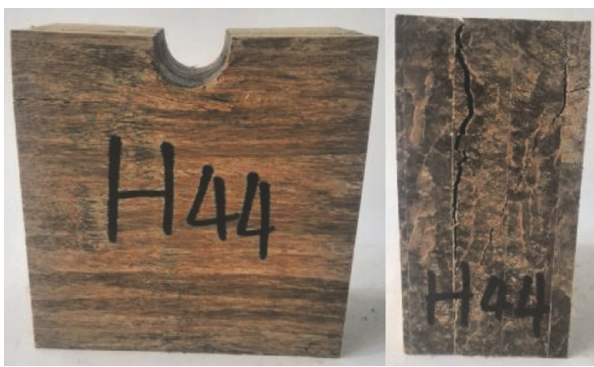

(a)

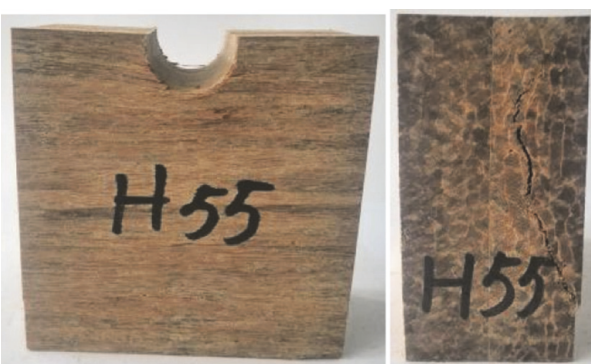

(b)

Figure 4: Typical failure mode of the specimen.

to grain, so more works are needed to be done to know about the mechanical behavior of PSB. To achieve the aim of this study, 40 specimens divided into 5 groups in terms of bolt diameter were tested to investigate the dowel-bearing property of PSB; based on the experiment and computational analysis, the formula for calculating the embedding strength will be proposed for PSB perpendicular to grain.

\section{Test Procedure}

PSB emerged recently as a new construction material; there are no tested criterion and method for PSB, concerning about similar mechanical performance as engineering wood, and the test method for engineering wood was employed to test the PSB material.

According to ASTM D5764-97a [24], tests were conducted by a square PSB block with a half-circle-hole perpendicular to grain located in the top face and a hole of $1.0 \mathrm{~mm}$ larger than the fastener diameter. All the specimens were same in dimension with $100 \mathrm{~mm}$ length, $50 \mathrm{~mm}$ width, and $100 \mathrm{~mm}$ height, except for the magnitude of the circle hole, and a detailed drawing of the specimen is shown in Figure 2. PSB has bigger density because of tremendous pressure in a higher temperature condition during the 


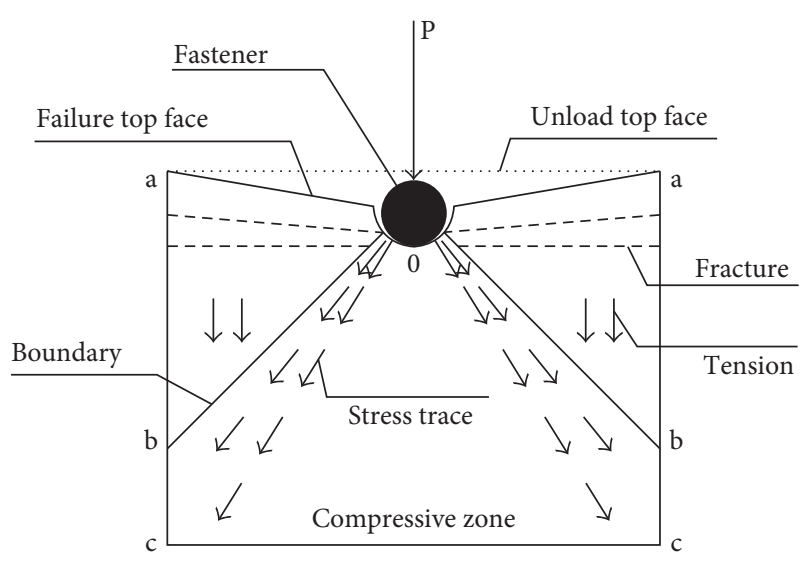

FIGURE 5: Stress state of the specimen.

manufacturing process, and the average tested value of gravity and moisture content are $1.08 \mathrm{~g} / \mathrm{cm}^{3}$ and $9.0 \%$, respectively, in terms of ASTM D2395 [25], and the average tested value of compression strength perpendicular to grain is $62 \mathrm{~N} / \mathrm{mm}^{2}$ according to ASTM D143-09 [26].

According to the experimental method provided by ASTM D5764-97a [24] for evaluating the embedding strength of wood and wood-based material, a controlled displacement of $1 \mathrm{~mm} / \mathrm{min}$ was adopted to apply the fastener till the specimen failure which can be defined that the side part PSB of hole meeting the loading plate and fastener embedded in PSB or load reaching $85 \%$ of the ultimate load. The laser displacement sensor (LDS) was employed to monitor the overall deformation of the specimen in the vertical direction, which is shown in Figure 3. Before the normal test, a small scale load was applied to check all devices at the start of the test.

\section{Test Result}

3.1. Failure Mode. When failure occurred, all fasteners were submerged into the specimen and the bearing zone under the fastener sank distinctly; unloaded PSB besides the fastener met the loading plate and cracked in the horizontal direction in all the specimens; PSB under the fastener bulged out of the plane; a vertical crack or a diagonal crack or both were observed in the broken specimen; the typical failure mode is shown in Figure 4.

The stress state of the specimen under loading is shown in Figure 5; the load was transferred though fastener from the loading plate to the specimen, and the bamboo fiber including under fastener and inside the stress dispersal boundary line was subjected to compressive force.

As shown in Figure 5, compression stress cannot reach the left and right zones oab, which is far away from the direct compressive zone $\mathrm{o}$ and is out of the stress dispersal boundary line; therefore, vertical deformation in zone oab is little. For zone obccb, especially contacting zone o, obvious deformation occurred on account of direct compression of the fastener; vertical deformation in zone bc brought out tension to bamboo fiber in zone obc; as a result, the horizontal fracture parallel to grain came out in zone ab, mainly near to the top face. Because of concentrated stress under fastener, bamboo fiber had large deformation in the vertical direction out of the grain plane, which results in bulking of bamboo out of the plane. Furthermore, the larger horizontal deformation brought out one or more fractures in bamboo fiber near fastener; with the increase of load, the fracture developed in the direction of two lateral edges and going down or sloping down; at the end, the specimen broke due to fracture which is shown in Figure 4.

Table 1 shows all the tested results. The dowel-bearing strength perpendicular to grain was obtained by the $5 \%$ fastener diameter offset method proposed in ASTM D5764$97 \mathrm{a}$ [24]. In this way, the load-displacement curve was obtained first in terms of tested data. A straight line fit to the initial linear portion of the load-displacement curve was offset by a deformation of $5 \%$ fastener diameter, and the load at which the offset line intersects the load-displacement curve was used as the yield load; finally, the yield load was divided by the bolt diameter and specimen thickness to get the embedding strength, and the method of obtaining yielding strength is shown in Figure 6. Table 1 gives the average value of each group specimen.

3.2. Strength-Displacement Curve. The strength-displacement curve of the 5 group specimens are shown in Figures 7-11. These curves in Figures 7 and 8 are for the bolt diameter of $12 \mathrm{~mm}$ and $14 \mathrm{~mm}$, respectively. It was obvious that the curve is similar in tendency and rises as the load increases, and at the end, the load stops due to the meeting between the loading plate and the top face of the specimen.

In two groups specimen of bigger diameter of $20 \mathrm{~mm}$ and $24 \mathrm{~mm}$, especially the group of $24 \mathrm{~mm}$ diameter, when the curve reached the summit value point, the dowel-bearing capacity started decreasing and obvious discreteness in peak load was observed. The previous phenomenon may be due to the following reasons: for groups $\mathrm{H} 1$ and $\mathrm{H} 2$ with a small bolt diameter, the interstice in PSB under load started diminishing, before the bolt was immersed into PSB, and the specimen was extruded to be compact; therefore, the embedding capacity increased constantly. Moreover, the loading path is shorter because of small diameter, and the loading will stop when the loading plate meets the top face of the specimen before the specimen was compacted well. This makes that the defect in structure and construction of the specimen did not display during the test.

As for groups $\mathrm{H} 4$ and $\mathrm{H} 5$ with a bigger bolt diameter, due to the longer loading path, fracture perpendicular to grain because of large deformation of internal bamboo fiber under increasing load comes after the PSB was extruded fully to be dense.

It is also observed that bolts with bigger diameter have larger bearing stiffness, and the bearing stiffness of group $\mathrm{H} 1$ is minimum and group $\mathrm{H} 5$ is maximum. Because bolts with bigger diameter have larger bearing area, the deformation of the specimens under a larger bolt is less than that of the specimens under a smaller bolt in the same load.

According to the tested results in Table 1, it is shown that even the yielding strength of each group decreased with the 
TABLE 1: Tested result.

\begin{tabular}{|c|c|c|c|c|c|c|c|c|c|c|}
\hline Specimen group & Number & Diameter of bolt (mm) & (1) & (2) & (3) & (4) & (5) & $\begin{array}{c}\text { (6) } \\
\text { (1)/(3) }\end{array}$ & $\begin{array}{c}\text { (7) } \\
\text { (1)/4) }\end{array}$ & $\begin{array}{c}\text { (8) } \\
\text { (5)/(1) }\end{array}$ \\
\hline H1 & 8 & 12 & 80.84 & 5.88 & 72.16 & 68.42 & 133.26 & 1.12 & 1.18 & 1.65 \\
\hline $\mathrm{H} 2$ & 8 & 14 & 77.40 & 8.42 & 68.61 & 63.34 & 114.30 & 1.13 & 1.22 & 1.48 \\
\hline $\mathrm{H} 3$ & 8 & 16 & 76.52 & 10.63 & 65.25 & 59.26 & 105.35 & 1.17 & 1.29 & 1.38 \\
\hline $\mathrm{H} 4$ & 8 & 20 & 74.20 & 12.20 & 59.04 & 53.00 & 99.32 & 1.26 & 1.40 & 1.34 \\
\hline H5 & 8 & 24 & 67.01 & 13.34 & 53.42 & 48.38 & 84.54 & 1.25 & 1.39 & 1.26 \\
\hline
\end{tabular}

Note. (1) is the average value of yielding strength based on the $5 \%$ bolt diameter offset method (MPa). (2) is the variable coefficient of tested yielding strength (\%). (3) is the calculating value of formula in BS EN 1995 (MPa). (4) is the calculating value of formula in NDS-2015 (MPa). (5) is the average value of ultimate tested strength $(\mathrm{MPa})$.

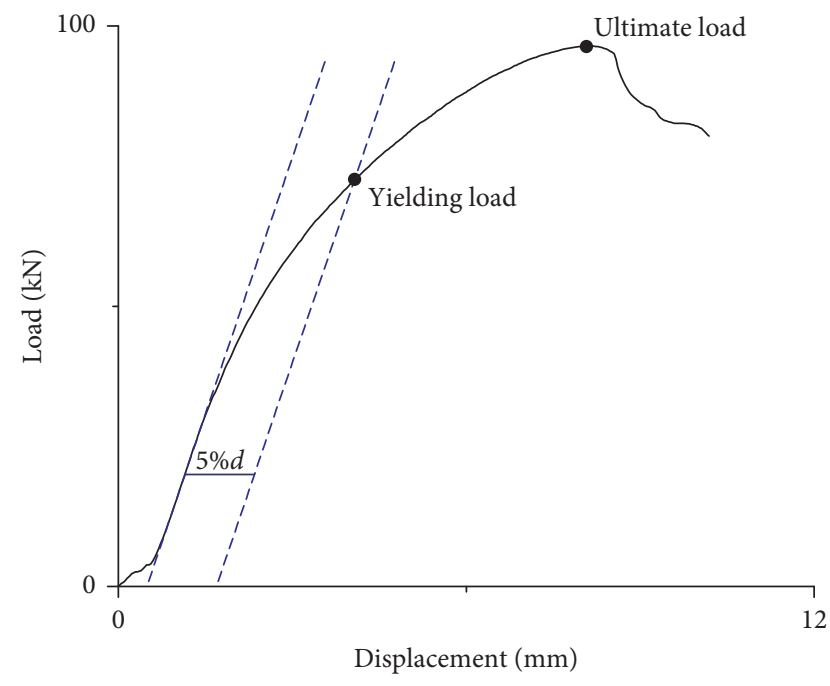

Figure 6: Method to evaluate the yielding load.

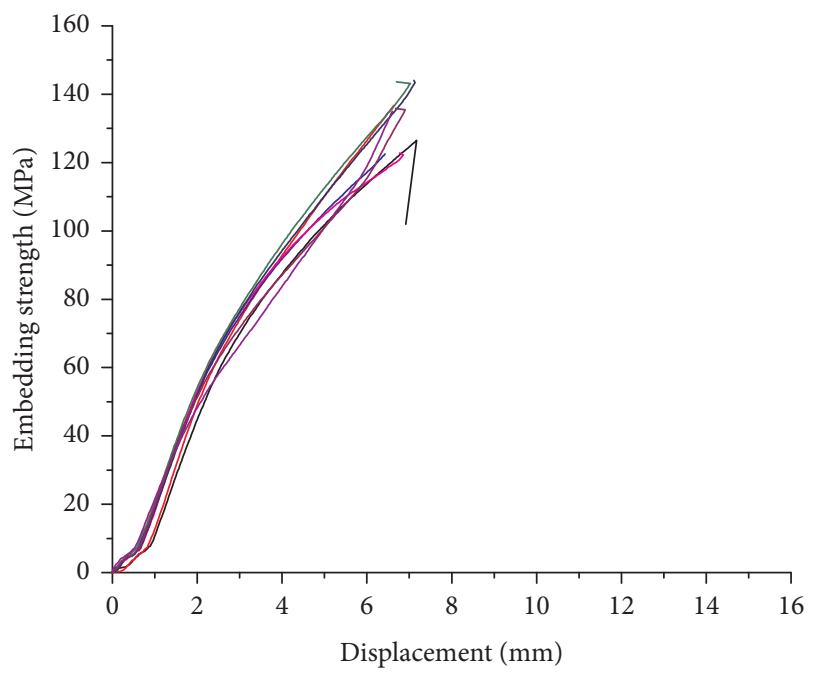

FiguRE 7: Strength-displacement curve of group H1.

increase in bolt diameter, which demonstrates that the magnitude of bolt has pronounced effect on dowel-bearing strength, which is in agreement with the tested results of Sawata and Yasumura [20]. Furthermore, the variable coefficient enlarges as the bolt diameter increases, which are in agreement with regularities of distribution of strengthdisplacement of the specimen.

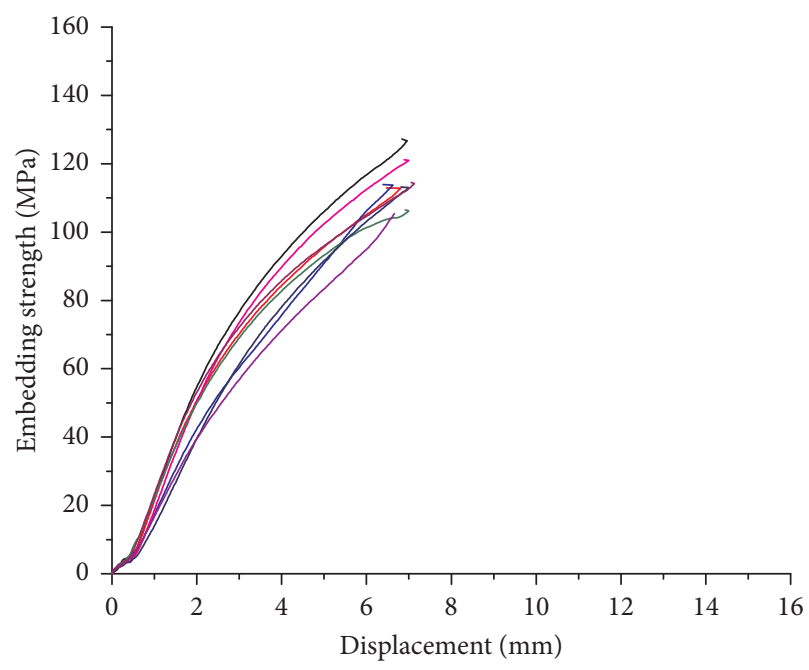

FIGURE 8: Strength-displacement curve of group H2.

In addition, from Table 1 , it is also observed that the ratio between the maximum bearing strength and yielding strength of $5 \%$ diameter offset decreased with the increase in bolt diameter, which indicated that bolted connection in small bolt diameter that has larger bearing capacity was calculated with the yielding strength of $5 \%$ diameter offset.

3.3. Bearing Capacity Perpendicular to Grain. The strengthdisplacement curve in Figures 7-11 showed that it is not easy to find the obvious yielding point in the curve; therefore, other approaches were needed to seek the yielding strength for engineering design. At present, the yielding strength in dowelbearing capacity was determined by the $5 \%$ diameter offset proposed in ASTM D5764-97a [24], which has already been accepted. The yielding strength value of each specimen is displayed in Figure 12, and the average value of yielding strength of each group specimen is displayed in Table 1. Due to higher cost and more time needed for on-site testing, BS EN 1995-1-1 [27] and NDS-2015 [28] both gave the calculating formula for the yielding value of dowel-bearing strength perpendicular to grain. In the formula proposed in BS EN 1995-1-1 [27], the embedding strength was based on the bolt diameter and material density and is shown as the following formula:

$$
f_{\mathrm{c}}=\frac{0.082(1-0.01 d) \rho_{\mathrm{k}}}{k_{90}} .
$$




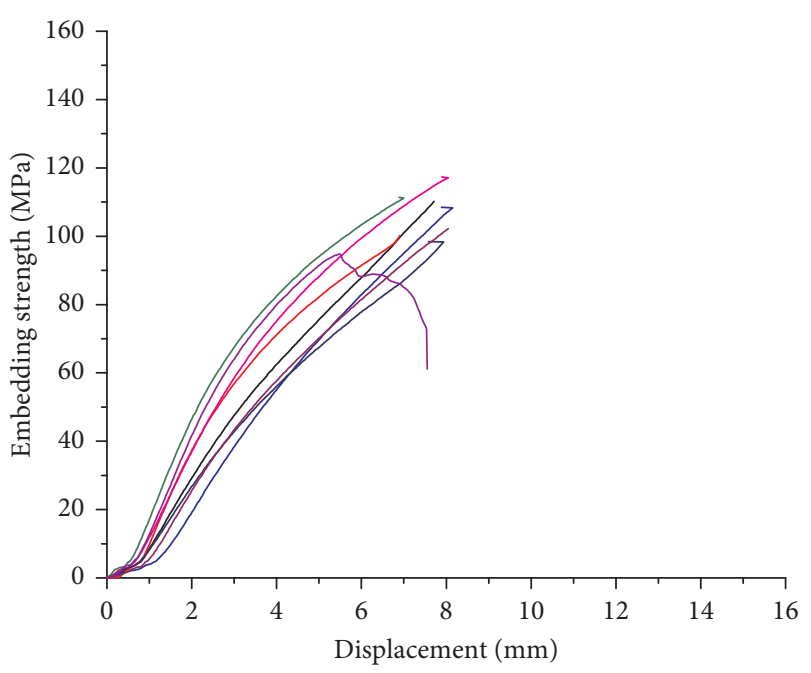

FIGURE 9: Strength-displacement curve of group H3.

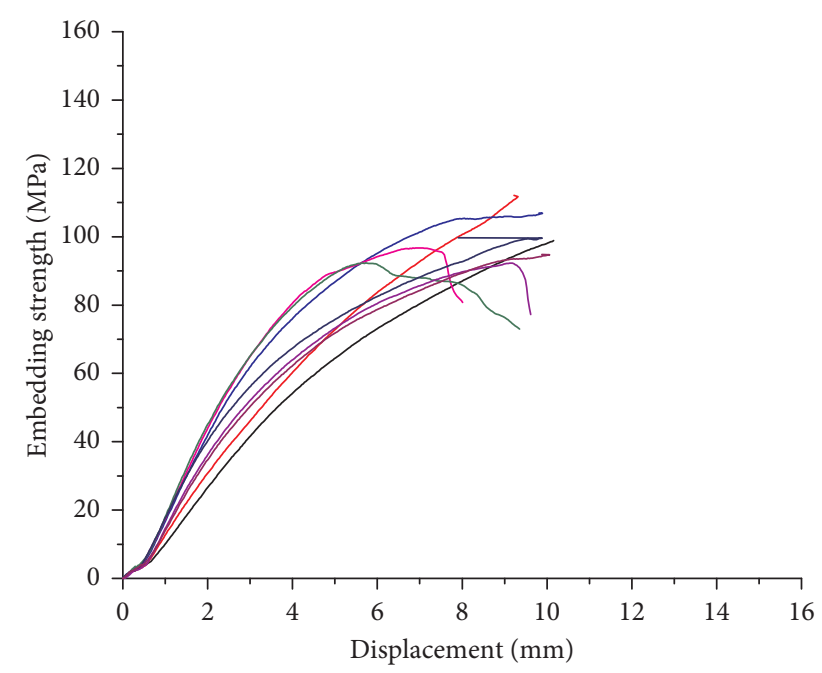

FIGURE 10: Strength-displacement curve of group H4.

For hardwoods,

$$
k_{90}=0.90+0.015 d,
$$

where $f_{c}$ is the dowel-bearing strength perpendicular to grain $(\mathrm{MPa}), d$ is the bolt diameter $(\mathrm{mm})$, and $\rho_{\mathrm{k}}$ is the density of wood $\left(\mathrm{kg} / \mathrm{m}^{3}\right)$.

In NDS-2015 [28], the dowel-bearing strength perpendicular to grain also concerning with bolt diameter and wood density is given by the following formula:

$$
F_{\mathrm{e}}=\frac{6100 G^{1.45}}{\sqrt{D}},
$$

where $F_{\mathrm{e}}$ is the dowel-bearing strength perpendicular to grain $\left((\mathrm{psi})^{2}\right), D$ is the bolt diameter (inch), and $G$ is the relative density of wood.

For contrasting analysis of (1) easily, (3) was substituted to obtain the following formula:

$$
f_{\mathrm{e}}=\frac{212 G^{1.45}}{\sqrt{D}}
$$

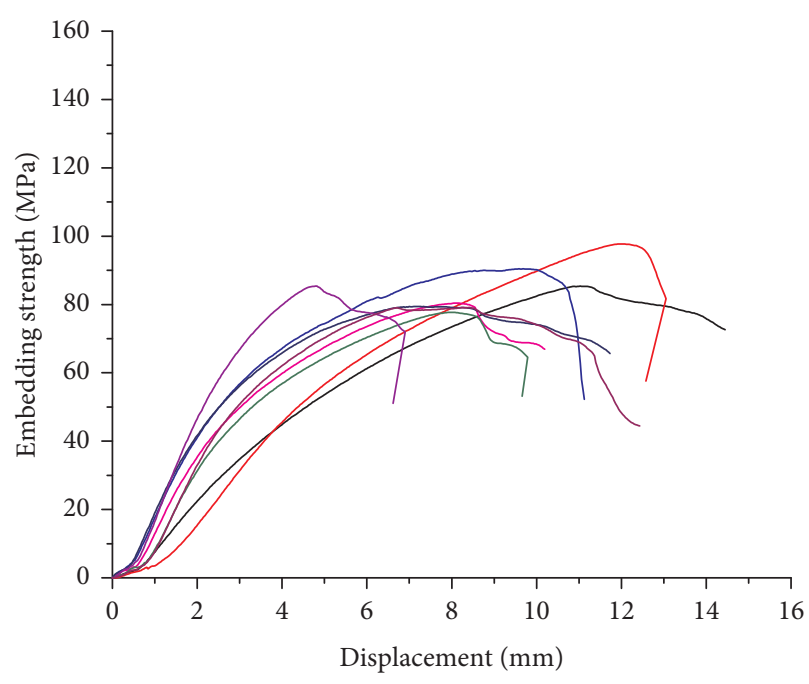

FIGURE 11: Strength-displacement curve of group H5.

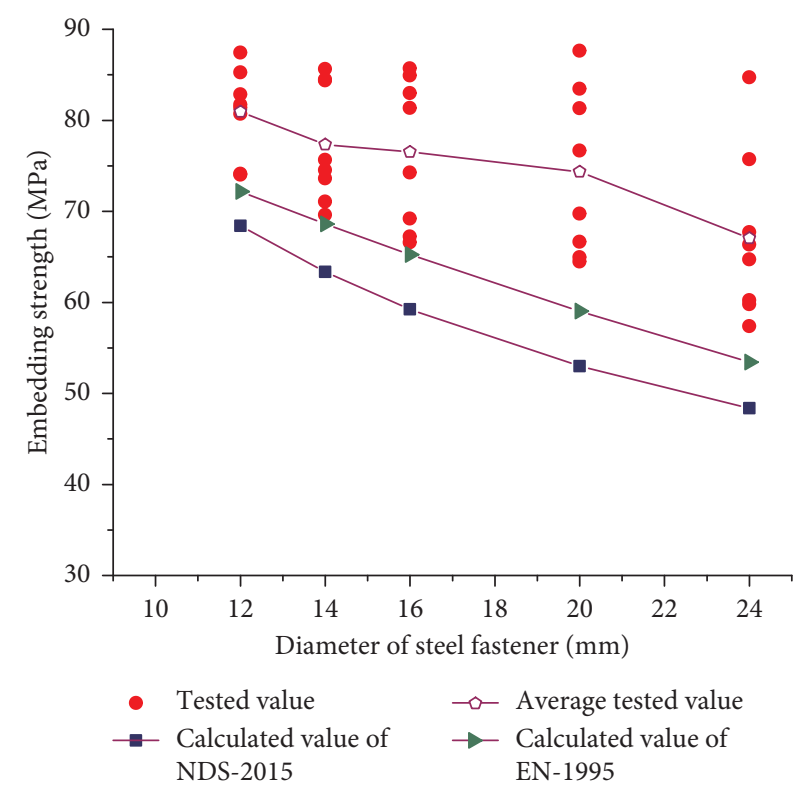

FIgURE 12: The comparison between the tested value and theoretical value.

where $f_{\mathrm{e}}$ is the dowel-bearing strength perpendicular to grain $(\mathrm{MPa}), D$ is the bolt diameter $(\mathrm{mm})$, and $G$ is the density of wood $\left(\mathrm{g} / \mathrm{cm}^{3}\right)$.

The value of embedding strength in terms of (1) and (4) is shown in Table 1.

As shown in Table 1, the embedding strength value according to the formula is smaller when bigger bolt diameter was applied, which is in accord with the tendency of tested results. Moreover, the average bearing strength in terms of $5 \%$ bolt diameter offsetting is approximately the calculated value for small diameter bolt and is the obvious gap for big diameter bolt. 
For PSB, the calculated value based on BS EN 1995-1-1 [27] is larger than that according to NDS-2015 [28] and approached the average tested result.

In Table 1 and Figure 12, the average tested values of 5 groups are all larger than the calculated values according to BS EN 1995-1-1 [27], which indicated that the dowelbearing yielding strength of PSB perpendicular to grain can be obtained by using the formula proposed in BS EN 1995-1-1 [27].

\section{Conclusions}

Five group specimens in a total number of 40 were tested to investigate the mechanical behavior of embedding strength of PSB perpendicular to grain, and strength-displacement curves of each specimen were provided in this paper. According to the previous curve, the tested embedding yielding strength was obtained by the $5 \%$ bolt diameter offset; meanwhile, the calculated embedding strength in terms of the NDS-2015 15 and BS EN 1995-1-1 was provided. Some conclusions were obtained as following.

(1) The certain relationship between the embedding strength of PSB perpendicular to grain and bolt diameter was observed; the bigger the bolt diameter, the smaller the embedding strength.

(2) The mechanical properties of PSB is stable, and the variable coefficient of embedding strength adopted $5 \%$ bolt diameter offset is between $5.88 \%$ and $13.34 \%$; moreover, the bigger the bolt diameter, the larger the variable coefficient.

(3) The average tested value of embedding yielding strength of PSB perpendicular to grain in accordance with the $5 \%$ bolt diameter is larger than the calculating value by using the formula proposed in NDS-2015 and BS EN 1995-1-1. So the method of using the calculating formula in BS EN 1995-1-1 or NDS-2015 to determine the embedding strength is feasible.

(4) The ratio between the tested ultimate strength and the yielding strength according to $5 \%$ bolt diameter offset decreased with the increase of bolt diameter.

\section{Conflicts of Interest}

The authors declare that they have no conflicts of interest.

\section{Acknowledgments}

The research was supported by the National Natural Science Foundation of China (nos. 51778299 and 51708049), the Project of Housing and Urban-Rural Development Ministry of China (no. 2014-K2-014), the Top-Notch Academic Programs Project of Jiangsu Higher Education Institutions (PPZY2015A041), the Science Foundation of Changzhou Institute of Technology (no. YN1615), and the Changzhou Sci \& Tech Program (no. CJ20179043).

\section{References}

[1] R. H. Falk, "Wood as a sustainable building material," Forest Products Journal, vol. 59, no. 9, pp. 6-12, 2009.

[2] M. Mahdavi, P. L. Clouston, and S. R. Arwade, "Development of laminated bamboo lumber: review of processing, performance, and economical considerations," Journal of Materials in Civil Engineering, vol. 23, no. 7, pp. 1036-1042, 2011.

[3] M. Green and J. E. Karsh, Tall Wood-the Case for Tall Wood Buildings, Wood Enterprise Coalition, Vancouver, Canada, 2012.

[4] S. Rittironk, Investigating Laminated Bamboo Lumbers Available Structural Material in Architectural Application, Illinois Institute of Technology, Chicago, IL, USA, 2009.

[5] S. Amada, Y. Ichikawa, T. Munekata, Y. Nagase, and K. Shimizu, "Fiber texture and mechanical graded structure of bamboo," Composites Part B: Engineering, vol. 28, no. 1-2, pp. 13-20, 1997.

[6] A. Porras and A. Maranon, "Development and characterization of a laminate com-posite material from polylactic acid (PLA) and woven bamboo fabric," Composites Part B: Engineering, vol. 43, no. 7, pp. 2782-2788, 2012.

[7] W. Fuli, Z. Shao, and W. Yijun, "Mode II interlaminar fracture properties of Moso bamboo," Composites Part B: Engineering, vol. 44, no. 1, pp. 242-247, 2013.

[8] L. Tingju, J. Man, J. Zhongguo, H. David, W. Zeyong, and Z. Zuowan, "Effect of surface modification of bamboo cellulose fibers on mechanical properties of cellulose/epoxy composites," Composites Part B: Engineering, vol. 51, pp. 28-34, 2013.

[9] F. Correal Juan, "Mechanical properties of Colombian glued laminated bamboo," in Proceedings of the 1st International Conference on Modern Bamboo Structures (ICBS'07), pp. 121127, Changsha, China, October 2007.

[10] Y. Wei, S. X. Jiang, Q. F. Lv, Q. S. Zhang, L. B. Wang, and Z. T. Lv, "Flexural performance of glued laminated bamboo beams," Advanced Materials Research, vol. 168-170, pp. 1700-1703, 2010.

[11] H.-T. Li, Q.-S. Zhang, D.-S. Huang, and A. J. Deeks, "Compressive per-formance of laminated bamboo," Composites Part B: Engineering, vol. 54, pp. 319-328, 2013.

[12] S. Arijit, W. Daniel, and M. Skyler, "Structural performance of glued laminated bamboo beams," Journal of Structural Engineering, vol. 140, no. 1, p. 04013021, 2014.

[13] H.-T. Li, J.-W. Su, Q.-S. Zhang, A. J. Deeks, and D. Hui, "Mechanical performance of laminated bamboo column under axial compression," Composites Part B: Engineering, vol. 79, pp. 374-382, 2015.

[14] Z. Aiping, H. Dongsheng, L. Haitao, and S. Yi, "Hybrid approach to determine mechanical parameters of fibers and matrixes of bamboo," Construction and Building Materials, vol. 35, pp. 191-196, 2012.

[15] D. S. Huang, A. P. Zhou, and Y. L. Bian, "Experimental and analytical study on the nonlinear bending of parallel strand bamboo beams," Construction and Building Materials, vol. 44, pp. 585-592, 2013.

[16] D. S. Huang, Y. L. Bian, A. P. Zhou et al., "Experimental study on stress-strain relationships and failure mechanisms of parallel strand bamboo made from phyllostachys," Construction and Building Materials, vol. 77, pp. 130-138, 2015.

[17] D. S. Huang, Y. L. Bian, D. M. Huang et al., "An ultimatestate-based-model for inelastic analysis of intermediate slenderness PSB columns under eccentrically compressive load," Construction and Building Materials, vol. 94, pp. 306314, 2015. 
[18] D. R. Rammer, "Parallel-to-grain dowel-bearing strength of two Guatemalan hardwoods," Forest Products Journal, vol. 49, no. 6, pp. 77-87, 2014.

[19] D. R. Rammer and S. G. Winistorfer, "Effect of moisture content on dowel bearing strength," Wood and Fiber Science, vol. 33, no. 1, pp. 126-139, 2001.

[20] K. Sawata and M. Yasumura, "Determination of embedding strength of wood for dowel-type fasteners," Journal of Wood Science, vol. 48, no. 2, pp. 138-146, 2002.

[21] S. Franke and N. Magnière, "The embedment failure of european beech compared to Spruce wood and standards," Materials and Joints in Timber Structures, vol. 9, no. 1, pp. 221-229, 2014.

[22] M. Schweigler, T. K. Bader, G. Hochreiner, G. Unger, and J. Eberhardsteiner, "Load-to-grain angle dependence of the embedment behavior of dowel-type fasteners in laminated veneer lumber," Construction and Building Materials, vol. 126, pp. 1020-1033, 2016.

[23] N. A. B. Seri, M. F. B. Nurddin, and R. B. Hassan, "Dowelbearing strength properties of glulam with and without glue line made of Mengkulang species," in InCIEC 2015, pp. 725-734, Springer, Berlin, Germany, 2016.

[24] American Society for Testing and Materials, Standard Test Method for Evaluating Dowel-Bearing Strength of Wood and Wood-Based Products (ASTM D5764-97a), ASTM, West Conshohocken, PA, USA, 2013.

[25] American Society for Testing and Materials, “ASTM D2395 Standard test methods for specific gravity of wood and woodbased materials," in Annual Book of ASTM Standard, ASTM, West Conshohocken, PA, USA, 2002.

[26] American Society for Testing and Materials, ASTM D143-09 Standard Test Methods for Small Clear Specimens of Timber, ASTM, West Conshohocken, PA, USA, 2009.

[27] British Standards Institution, BS EN 1995-1-1, Eurocode 5: Design of Timber Structures-Part 1-1: General-Common Rules and Rules for Buildings, BSI, London, UK, 2004.

[28] American National Standards Institute, NDS-2015 National Design Specification for Wood Construction, American Forest and Paper Association, Washington, DC, USA, 2012. 


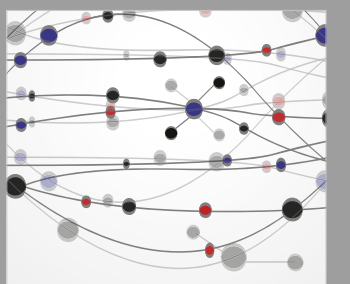

The Scientific World Journal
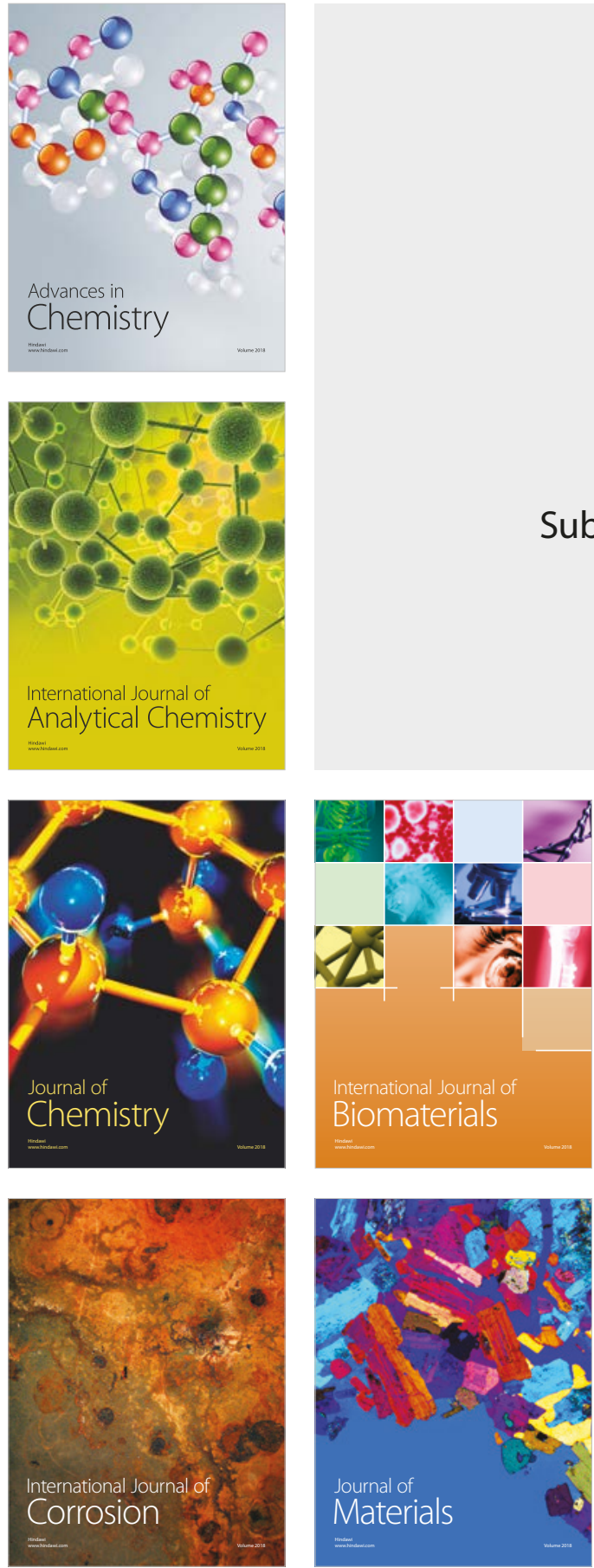

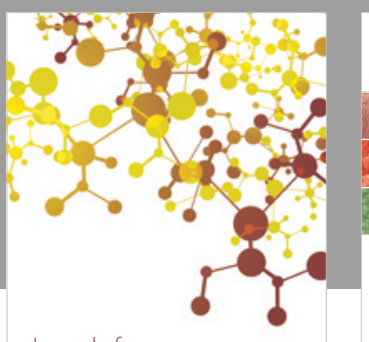

Journal of

Applied Chemistry
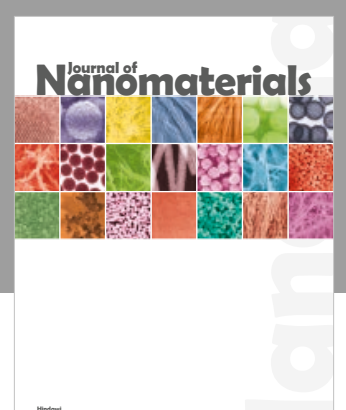

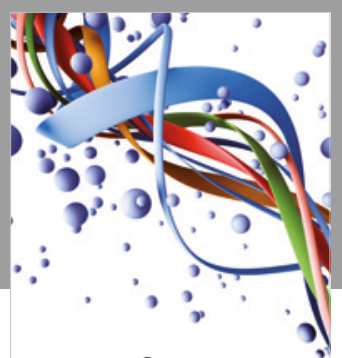

Scientifica

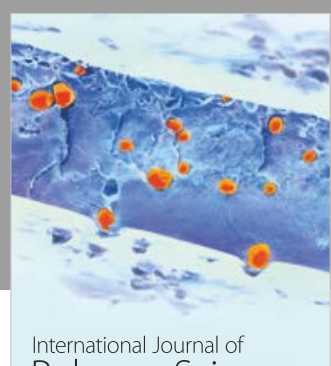

Polymer Science

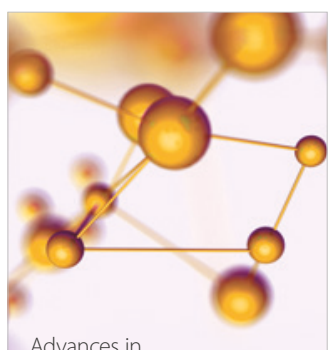

Physical Chemistry
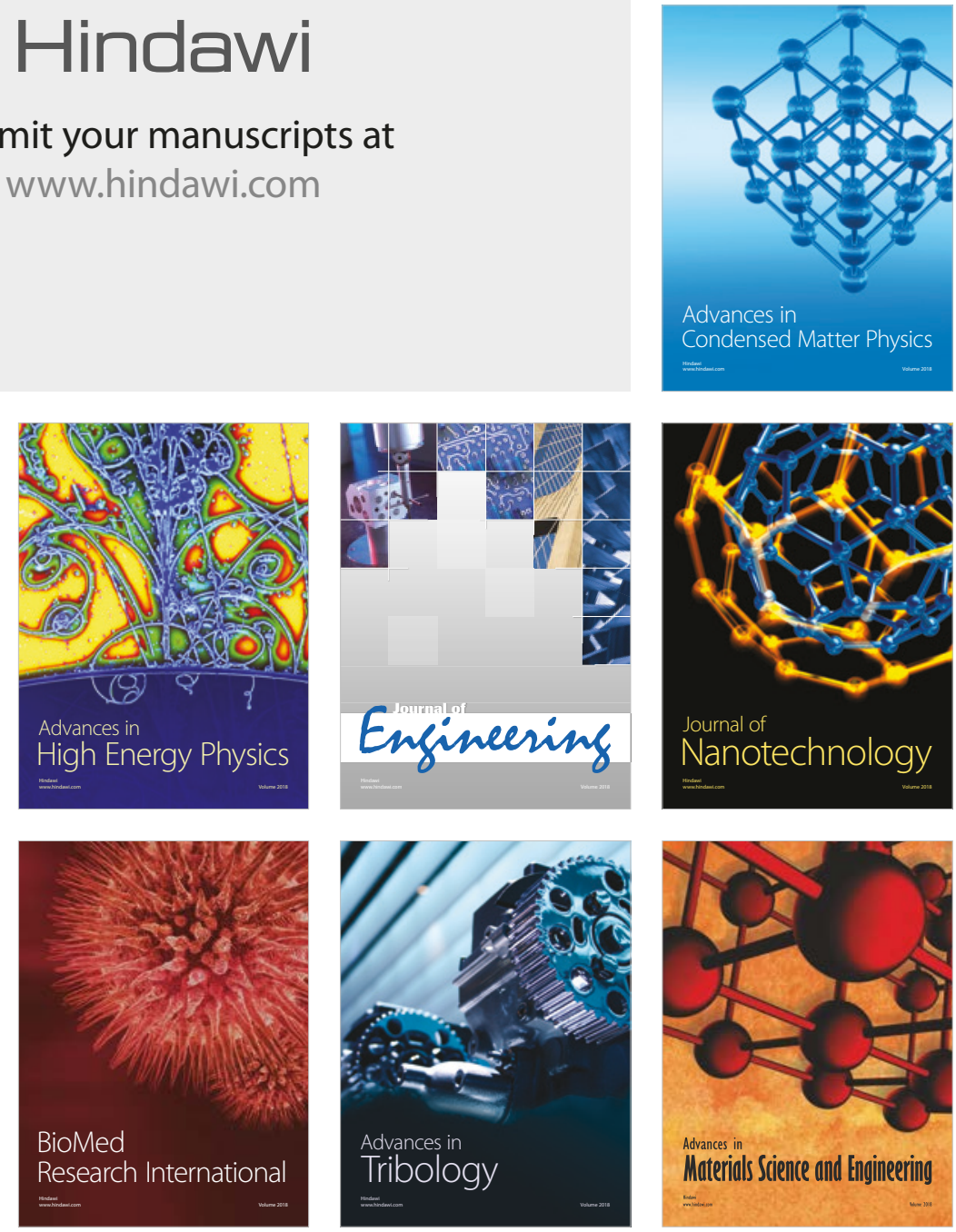